\title{
Development and Validation of the
}

Equanimity Scale-16

\section{Holly T. Rogers, Alice G. Shires \& Bruno A. Cayoun}

\section{Mindfulness}

ISSN $1868-8527$

Mindfulness

DOI 10.1007/s12671-020-01503-6 
Your article is protected by copyright and all rights are held exclusively by Springer Science+Business Media, LLC, part of Springer Nature. This e-offprint is for personal use only and shall not be self-archived in electronic repositories. If you wish to selfarchive your article, please use the accepted manuscript version for posting on your own website. You may further deposit the accepted manuscript version in any repository, provided it is only made publicly available 12 months after official publication or later and provided acknowledgement is given to the original source of publication and a link is inserted to the published article on Springer's website. The link must be accompanied by the following text: "The final publication is available at link.springer.com". 


\title{
Development and Validation of the Equanimity Scale-16
}

\author{
Holly T. Rogers ${ }^{1}$ (D) $\cdot$ Alice G. Shires ${ }^{1,2} \cdot$ Bruno A. Cayoun $^{2}$ \\ Accepted: 9 September 2020 \\ (C) Springer Science+Business Media, LLC, part of Springer Nature 2020
}

\begin{abstract}
Objectives Equanimity is a non-reactive attitude that is increasingly recognized as a central component of mindfulness practice and a key mechanism of mindfulness-based interventions that is currently lacking means of measurement. The present study aimed to develop a self-report measure of equanimity, explore its underlying factor structure, validity and reliability.

Methods An initial pool of 42 items was selected from existing mindfulness questionnaires and measures of related constructs, and subsequently reviewed by researchers and selected based on majority agreement on their construct validity. The Qualtrics online platform was used to administer these items and other questionnaires used to assess validity and collect demographic information in 223 adults from the general community $(66.8 \%$ females and $33.2 \%$ males, age range $=18-75)$. Questionnaires were then re-administered to assess test-retest reliability.

Results In agreement with past research, exploratory factor analysis revealed two underlying factors, Experiential Acceptance and Non-reactivity. A final 16-item measure showed good internal consistency $(\alpha=.88)$, test-retest reliability $(n=73 ; r=.87, p<$ $.001)$ over 2-6 weeks and convergent and divergent validity, illustrated by significant correlations in the expected direction with the Nonattachment Scale, Depression Anxiety and Stress Scale, Satisfaction with Life Scale and Distress Tolerance Scale.

Conclusions Based on this initial study, the Equanimity Scale-16 appears to be a valid and reliable self-report measure to assess trait equanimity, and may be further explored in future studies as a tool to assess progress during mindfulness-based interventions, and to assist in the investigation of their underlying mechanisms.
\end{abstract}

Keywords Equanimity $\cdot$ Mindfulness $\cdot$ Non-reactivity $\cdot$ Acceptance $\cdot$ Nonattachment $\cdot$ Equanimity Scale

Mindfulness is a skillset heavily informed by Buddhist contemplative tradition that has been defined in various ways, including as "close, clear-minded attention to, or awareness of, what is perceived in the present" (Quaglia et al. 2015, p. 4), as "paying attention in a particular way: on purpose, in the present moment, and non-judgmentally" (Kabat-Zinn 1994, p. 4), and as "selfregulation of attention" and an orientation "that is characterized by curiosity, openness and acceptance" (Bishop et al. 2004, p. 232). There has been increasing interest in mindfulness over the last few decades (Williams and Kabat-Zinn 2011), during which mindfulness-based interventions (MBIs) have been developed to address a range of mental health conditions. These include Mindfulness Based Stress Reduction (Kabat-Zinn 1990),

Alice G. Shires

Alice.Shires@uts.edu.au

1 University of Technology, Sydney, Australia

2 MiCBT Institute, Hobart, Australia
Mindfulness Based Cognitive Therapy (Segal et al. 2002), Mindfulness-Integrated Cognitive Behavior Therapy (MiCBT; Cayoun 2011), Mindfulness Based Symptoms Management (Monteiro and Musten 2013), Meditation Awareness Training (Shonin et al. 2014) and Mindfulness-Based Positive Behavior Support (Singh et al. 2014).

There have been an increasing number of validated selfreport mindfulness questionnaires produced with at least eight widely used (Bergomi et al. 2013a). Researchers have presented one (attention/awareness; Brown and Ryan 2003), two (awareness and acceptance; Cardaciotto et al. 2008), three (intention, attention and attitude; Shapiro et al. 2006), four (observe, describe, awareness and acceptance without judgment; Baer et al. 2004) and five (observe, describe, awareness, non-judgement and non-reactivity; Baer et al. 2006) factor models. Additionally, questionnaires also vary based on the population for which they were intended and whether they are measuring state or trait mindfulness. In comparing mindfulness questionnaires, researchers found that correlations between five widely used measures were very heterogeneous (Baer et al. 
2006; Cardaciotto et al. 2008), likely due to differing conceptualizations and therefore operationalizations. While having a choice of mindfulness questionnaires to be used in differing contexts can be seen as a strength and many have good psychometric properties (Baer et al. 2009), each appears to conceptualize mindfulness in a different way, resulting in concerns with content validity (Grossman 2011), making comparisons between studies difficult.

A range of models have been proposed to account for the link between MBIs and positive outcomes (see Gu et al. (2015) for a review). The combined skill of monitoring and acceptance has been suggested to be a key mechanism of beneficial change (Cayoun et al. 2020; Lindsay and Creswell 2017). A meta-analysis found strong and consistent support for the claim that cognitive and emotional reactivity mediates the relationship between MBIs and positive outcomes (Gu et al. 2015), and the mechanisms of acceptance and reactivity also appear in a number of models and reviews of the literature (Baer 2003; Brown et al. 2007; Grabovac et al. 2011; Hölzel et al. 2011; Shapiro et al. 2006).

The Buddhist psychological model (BPM; Grabovac et al. 2011), explains that when we become aware of an object, there is an associated feeling tone (pleasant, unpleasant, or neutral), highlighting the importance of interoceptive awareness as a key function in mindfulness practice (Farb et al. 2015; Hölzel et al. 2011). This model advances that we respond habitually by pursuing pleasant experiences and avoiding unpleasant experiences, triggering a downward cascade of thoughts and emotions (mental proliferation), leading to suffering. Accordingly, while unpleasant experiences are inherent in life, suffering increases based on the way in which one relates to these experiences, through craving pleasant experiences and avoiding unpleasant ones (Teasdale and Chaskalson 2011). This is supported by evidence that experiential avoidance is detrimental to one's well-being (Hayes et al. 1996). The BPM suggests that mindfulness practice leads to insight into three fundamental components of Buddhist teachings (impermanence of all phenomena, the inexistence of selfhood or "egolessness", and the suffering that occurs when impermanence and egolessness are ignored). However, one of the conditions for the development of such insight through mindfulness is the coupling between awareness and equanimity (Eberth et al. 2019; Hart 1987), which prevents attachment to pleasant experiences and aversion to unpleasant ones, and thus reduces mental proliferation and associated suffering (Grabovac et al. 2011). Interoceptive awareness has been identified as a key mechanism of MBIs (Farb et al. 2015; Hölzel et al. 2011), as one's habitual reactions to attach to or avoid experiences are in response to the feeling tone, rather than the stimulus itself (Cayoun et al. 2019; Grabovac et al. 2011).

Equanimity is an attitude that is increasingly recognized as a component of mindfulness practice that is inseparable from experiential awareness (Eberth et al. 2019). Equanimity is described in the Buddhist literature as "a balanced reaction to joy and misery, which protects one from emotional agitation" (Bodhi 2005, p. 154). Equanimity has also been conceptualized as an "even minded mental state or dispositional tendency towards all experiences or objects, regardless of their affective valence (pleasant, unpleasant or neutral) or source" (Desbordes et al. 2015, p. 357). In its behavioral conceptualization, equanimity has been considered to be the central mechanism of change in mindfulness practice because it is the non-reactive stance that prevents attachment (craving) and avoidance (aversion) while exposed to an internal or external trigger, thereby producing an extinction response during unwanted experiences (Cayoun 2011).

Others point towards similar observations, suggesting that acceptance and non-reactivity are central mechanism of MBIs (Eberth et al. 2019; Gu et al. 2015; Lindsay et al. 2018). Mindfulness is also believed to be the first step to developing equanimity (Weber 2017). Whereas mindfulness allows present-moment experiential awareness, equanimity allows an even-minded (and therefore more objective) perception of the experience, through an attitude which does not seek to resist or attach to the experience (Desbordes et al. 2015). Consequently, mindfulness skills develop as a function of equanimity. While equanimity has been described using words such as "detachment", it should not be mistaken with indifference or apathy, which Buddhist scholars describe as the "near enemy" of equanimity (Bodhi 2000, p. 87). Detachment, in the context of equanimity, refers to the elimination of craving and aversion from experience, suggesting a degree of attentiveness and care. In contrast, indifference is described as a detrimental mental state driven by ignorance (Desbordes et al. 2015).

The Decoupling model of equanimity defines equanimity as the decoupling of desire (wanting vs. not wanting) and hedonic tone (pleasant vs. unpleasant), suggesting that in states of high equanimity desire is based on values, prosocial intentions and long-term goals, while in states of low equanimity desire is based on hedonic tone (Hadash et al. 2016). Equanimity is therefore manifested in an "intentional attitude of acceptance towards experience regardless of its hedonic tone", and "reduced autonomic reactivity to the hedonic tone of experience" (Hadash et al. 2016, p. 4). This definition shares similarities to that presented by Desbordes et al. (2015). In testing their model, Hadash et al. (2016) examined whether acceptance and reduced reactivity, measured indirectly using pre-existing questionnaires, reflect manifestations of a latent construct which they proposed was equanimity. In their community sample $(N=191)$, the authors found one higher order factor of equanimity and two lower order factors of reduced reactivity and an attitude of acceptance, and that development of mindfulness was associated with increased equanimity, which supported their model. While this study 
provided a clarified conceptualization of equanimity, the construct was measured indirectly using existing measures of distress tolerance and thought suppression to assess acceptance, and anxiety sensitivity and cognitive reactivity to sad mood to assess reactivity. This highlights the need for a dedicated measure of equanimity.

Equanimity appears to involve both the prevention of emotional reactivity and the acceptance of one's direct experience, as reflected in interoception (Hart 1987). For example, one may be reacting emotionally due to grief while fully accepting that they are doing so. In this case, acceptance is associated with reactivity and cannot constitute equanimity. Similarly, one may be non-reactive after the loss of a parent or the end of a relationship while at the same time being unable to accept their lack of emotional closeness with the departed. Hence, reactivity and acceptance are understood as both interrelated and different constructs.

In terms of related measures, Büssing et al. (2007) developed a 40-item scale of non-institutional spirituality, which they administered to 488 hospital staff and individuals from different religious communities. The authors suggested that equanimity was one of seven distinct aspects of spirituality. However, items were "trying to practice equanimity", "trying to achieve a calm spirit" and "meditate", which conceptualized efforts to cultivate equanimity, rather than equanimity itself. Additionally, it could be questioned whether all individuals would understand the term equanimity in such items as "trying to practice equanimity", and therefore be able to accurately rate their efforts towards it.

Lundman et al. (2007) defined equanimity as a balanced perspective on one's life and suggested it to be one of five components that make up resilience, in exploring the underlying factor structure of the 25-item Resilience Scale (Wagnild and Young 1993). The authors found the model to be psychometrically valid and the factor structure was consistent with theory in a diverse sample $(N=1719)$. However, equanimity items captured present focus, acceptance and an optimistic approach, all of which represent either part or peripheral aspects of equanimity and do not capture its entirety, missing the central concept of non-reactivity which is proposed by Hadash et al. (2016) and others (Cayoun 2011; Desbordes et al. 2015; Hart 1987). Similarly, while the 12-item Peace, Equanimity, and Acceptance in the Cancer Experience (PEACE) (Mack et al. 2008) Scale was statistically valid and reliable in a sample of 160 adults with advanced cancer, items did not fully capture the concept of equanimity as explained above.

Kraus and Sears (2009) developed a scale to measure the Buddhist psychological constructs of the "four immeasurables", which consist of equanimity, loving-kindness, sympathetic joy and compassion. However, equanimity was only measured with one variable (acceptance towards self and others), which, as previously mentioned, captures only part of the construct of equanimity. More specifically, respondents are asked to rate items on a Likert scale according to the extent that they have thought, felt or acted in a way that is "friendly", "hateful", "angry", "joyful”, "accepting", "cruel”, "compassionate" or "mean" towards themselves and others during the past week. The element of non-reactivity is not emphasized. More robust evidence is also needed for this instrument, as it was tested in a sample of 124 students and we are not aware of other psychometric studies of this questionnaire.

More recently, the Equanimity Barriers Scale (EBS; Weber and Lowe 2018) was developed. This instrument is a 15-item self-report questionnaire to measure barriers that individuals encounter in developing equanimity, rather than an individual's degree of equanimity. Hence, apart from the EBS, operationalizations of equanimity have generally been based on subscales with items that lack precision or do not reflect the entirety of the construct, and we are not aware of any measure that captures an individual's self-reported level of equanimity. Additionally, examining previous mindfulness questionnaires reveals that while some definitions share similarities with equanimity, none adequately captures the construct as a whole (Hadash et al. 2016), which necessitates the development of a more specific measure, as suggested by others (Desbordes et al. 2015).

The principal aim of the present study was to develop a self-report measure of equanimity using items from existing questionnaires conceptually related to equanimity and assess its factor structure and validity in a general community sample. We first hypothesized that the structure would be congruent with traditional Theravada conceptualization (Hart 1987) and Hadash et al.'s (2016) two-factor model, comprising one factor of acceptance and one factor of non-reactivity. Psychometric properties were tested by examining internal consistency, construct validity and test-retest reliability over a 2- to 4-week period. Regarding convergent and divergent validity, it was hypothesized that the measure would show significant positive correlations with the Nonattachment Scale, the Satisfaction with Life Scale and the Distress Tolerance Scale, and significant negative correlations with the Depression Anxiety and Stress Scale.

\section{Methods}

\section{Participants}

Participants consisted of 223 adults from the general community and the University of Technology, Sydney (UTS). Participants were recruited from advertising around the UTS campus, advertising on social media, an email to the Australian Clinical Psychology Association mailing list and through peer referral. Participants were included in the study if they were aged 18 years or over. There were no other exclusion criteria than being below age 18. Participant demographics are presented in Table 1. Participants had a wide 
Table 1 Participant demographics

\begin{tabular}{|c|c|c|}
\hline Characteristic & $N$ & $\%$ \\
\hline \multicolumn{3}{|l|}{ Age (years) } \\
\hline $18-25$ & 31 & 13.9 \\
\hline $26-35$ & 56 & 25.1 \\
\hline $36-45$ & 26 & 11.7 \\
\hline $46-55$ & 37 & 16.6 \\
\hline $56-65$ & 56 & 25.1 \\
\hline $66-75$ & 15 & 6.7 \\
\hline \multicolumn{3}{|l|}{ Gender } \\
\hline Male & 74 & 33.2 \\
\hline Female & 149 & 66.8 \\
\hline Other/prefer not to disclose & 0 & 0.0 \\
\hline \multicolumn{3}{|l|}{ Work status } \\
\hline Full time & 98 & 43.9 \\
\hline Part time & 33 & 14.8 \\
\hline Casual & 20 & 9.0 \\
\hline Self-employed & 42 & 18.8 \\
\hline Unemployed & 30 & 13.5 \\
\hline \multicolumn{3}{|l|}{ Relationship status } \\
\hline Married/de-facto & 144 & 64.6 \\
\hline Separated/divorced & 14 & 6.3 \\
\hline Single & 59 & 26.5 \\
\hline Widowed & 6 & 2.7 \\
\hline \multicolumn{3}{|l|}{ Education } \\
\hline High school & 16 & 7.2 \\
\hline Trade/apprenticeship & 18 & 8.1 \\
\hline Diploma & 18 & 8.1 \\
\hline Undergraduate & 43 & 19.3 \\
\hline Postgraduate & 128 & 57.4 \\
\hline \multicolumn{3}{|l|}{ Ethnicity } \\
\hline African American & 0 & 0.0 \\
\hline Asian & 12 & 5.4 \\
\hline Caucasian & 189 & 84.8 \\
\hline Hispanic & 1 & 0.4 \\
\hline Indian/Pakistani & 4 & 1.8 \\
\hline Other & 17 & 7.6 \\
\hline
\end{tabular}

range of ages, were generally engaged in full-time work, the majority were married or in de-facto relationships and indicated a postgraduate level education, most identified as Caucasian, and females were the majority. The sample size appears adequate for the purpose of this study. Tabachnick and Fidell (2001) suggest that 5 participants per item are sufficient, especially if the number of factors is low. Comfrey and Lee (1992) suggest that 200 participants is fair and 300 is good. From this initial sample, 88 participants also completed a second administration to assess test-retest reliability. This involved re-administering the same questionnaires $2-4$ weeks later to determine if responses were consistent over time.

\section{Procedures}

The study gained approval of the UTS Human Research Ethics Expedited Review Committee (approval number 2015000482-74). Participants accessed the survey online, hosted on the Qualtrics platform, and were required to read the participant information sheet and indicate whether they were over 18-year-old and agreeing to participate. Informed consent was obtained from all participants. The demographics questionnaire, Equanimity Scale-42 (development described below), Nonattachment Scale (NAS; Sahdra et al. 2010), Depression, Anxiety and Stress Scale (DASS-21; Lovibond and Lovibond 1995), Marlowe-Crowne Social Desirability Scale-Short Form (MC-10; Strahan and Gerbasi 1972), Satisfaction with Life Scale (SWLS; Diener et al. 1985) and Distress Tolerance Scale (DTS; Simons and Gaher 2005) were then administered. Participants also had the option of leaving their email address to be contacted for the second administration of the survey to collect test-retest reliability data, which initially took place 2-4 weeks later. Seven of the initial 88 cases were not included in the analysis as responses could not be matched between time points. Additionally, the time between administrations was extended from 2-4 weeks to 2-6 weeks to include participants who responded slightly outside of the initial time period. An additional eight cases were further excluded as their responses were far outside the initial time period (6+ weeks), resulting in a final sample size of 73 participants.

\section{Questionnaire Development}

The items to construct the current instrument were selected from twenty existing self-report questionnaires measuring mindfulness and related constructs. These were chosen on the basis that some of their items were conceptually related to equanimity. Items that were most representative of equanimity according to both contemplative traditions and current authors in mindfulness science, as described above, were extracted. This procedure was used based on our observation that these items were theoretically consistent with the construct of equanimity and developing additional items would have required an approximate replication of these items, rather than adding precision or variety to the item pool. These questionnaires were the Cognitive and Effective Mindfulness Scale-Revised (Feldman et al. 2007), Comprehensive Inventory of Mindfulness Experiences Beta (Bergomi et al. 2013b), Difficulties in Emotion Regulation Scale (Gratz and Roemer 2004), Experiences Questionnaire (Fresco et al. 2007), Five Facet Mindfulness Questionnaire (Baer et al. 2006), Freiburg Mindfulness Inventory (Buchheld et al. 2001), Kentucky Inventory of Mindfulness Skills (Baer et al. 2004), Langer Mindfulness Scale (Pirson and Langer 2015), Mindful Attention Awareness Scale (Brown and Ryan 2003), 
Mindfulness Self Efficacy Scale-Revised (Cayoun et al. 2012), Multidimensional Assessment of Interceptive Awareness (Mehling et al. 2012), Multidimensional Mindfulness Inventory (Dyer and Cayoun 2012; unpublished inventory), Peace, Equanimity, and Acceptance in the Cancer Experience (Mack et al. 2008), Personal Functioning Inventory (Kohn et al. 2003), Philadelphia Mindfulness Scale (Cardaciotto et al. 2008), Resilience Scale (Wagnild and Young 1993, as cited in Lundman et al. 2007), Self-Other Four Immeasurables (Kraus and Sears 2009), Southampton Mindfulness Questionnaire (Chadwick et al. 2008), State Mindfulness Scale (Tanay and Bernstein 2013) and Toronto Mindfulness Scale (Lau et al. 2006).

In total, this formed an initial item pool of 517 items, which were then reviewed by the authors. In relation to the level of experience, two of the three authors of this study have extensive experience of mindfulness meditation and the development of equanimity through daily personal practice and teaching in insight traditions (over 30 years for one and 14 years for the other). A priori criteria for item acceptance and rejection was initially used. Based on traditional and scientifically derived definitions of equanimity, items were retained only if they contained elements of Experiential Acceptance and Non-reactivity, or their opposite (unacceptance and reactivity). Items that at least two out of three authors endorsed as representing equanimity, as it has been outlined above, were retained and sent to an external reviewer with the relevant expertise for an independent third assessment. The final item pool consisted only of items that at least three out of four researchers endorsed as representative of equanimity. Two additional items were developed to represent equanimity towards all experiences (e.g. including physical discomfort) and equanimity when faced with craving as well as aversion. Adjustments to the wording of some items were then made, to change past tense into present tense, to make items simpler or more interpretable and to word some items negatively. Following this revision, the item pool comprised of 42 items, which were retained and will be referred to as the "Equanimity Scale-42" (ES-42). Items rated on a 5point Likert scale from 1 (Strongly Disagree) to 5 (Strongly Agree), providing a total score ranging from 42 to 210 , with higher scores representing higher equanimity.

\section{Measures}

\section{Demographics}

The demographics questionnaire collected information about age, gender, work status, relationship status, education and ethnicity (see Table 1). Participants were requested to enter a unique identifying code, consisting of their first and last name initials along with their year of birth (e.g. HG67), so that data could be matched between time points for test-retest reliability assessment.

\section{Nonattachment}

The Nonattachment Scale (NAS; Sahdra et al. 2010) is a 30item self-report questionnaire measuring nonattachment. Items are rated on a 6-point Likert scale from 1 (Disagree Strongly) to 6 (Agree Strongly). Scores range from 30 to 180, with higher scores representing higher Nonattachment. Nonattachment is described as not being "stuck" or fixated on experiences (images, sensory objects or ideas) and not feeling a pressure to control these experiences. Similarly, the concept of equanimity involves non-reactivity to experiences preventing attachment or aversion to these experiences (e.g. thoughts, feelings); therefore, this construct was used to assess convergent validity as it is conceptually close to equanimity and therefore high levels of nonattachment are predicted to be associated with high levels of equanimity. The NAS was shown to have high internal consistency $(\alpha=.93)$, adequate test-retest reliability $(r=.87$, $p<.0001)$ and convergent and divergent validity in a college student sample, and significant groups validity in an online USwide study (Sahdra et al. 2010).

\section{Negative Affect and Emotional Reactivity}

The Depression, Anxiety and Stress Scale (DASS-21; Lovibond and Lovibond 1995) is a widely used 21-item self-report measure of depression, anxiety and stress symptoms. Items are rated on a 4-point Likert scale from 0 (Not at all) to 3 (Very much or most of the time) and form the subscales of depressive, anxiety and stress symptoms. Each subscale has possible scores between 0 and 21, with higher scores representing higher pathology along these dimensions. Given that the subscales of the DASS-21 measure separate constructs, the subscale scores were used for analyses, instead of an overall score. The DASS- 21 was selected as a measure of divergent validity, as MBIs are associated with reductions in psychological symptoms (Baer 2003; Hofmann et al. 2010) and equanimity is suggested to be an important mechanism in these interventions (Cayoun 2011; Desbordes et al. 2015). Therefore, high levels of equanimity are predicted to be associated with low levels of psychopathology and emotional reactivity. The DASS-21 subscales have shown good to excellent internal consistency ( $\alpha=.87$ to .94 ) and concurrent validity in clinical and non-clinical samples (Antony et al. 1998).

\section{Social Desirability}

The Marlowe-Crowne Social Desirability Scale-Short Form (MC-10; Strahan and Gerbasi 1972) is a 10-item self-report questionnaire assessing an individual's tendency to respond in a socially desirable way. Items are rated as True or False, with scores ranging from 0 to 13 . Higher scores represent a high degree of socially desirable responding. This questionnaire was used to assess whether individuals responded to the ES 
items in a socially desirable way. The MC-10 has shown high internal consistency $(\alpha=.88)$, high correlation with the original full scale $(r=.96)$, and has been proposed as a significant improvement over the original scale and other short forms when tested in a sample of psychology university undergraduates (Fischer and Fick 1993).

\section{Life Satisfaction}

The Satisfaction with Life Scale (SWLS; Diener et al. 1985) is a 5-item self-report questionnaire assessing individual's satisfaction with life as a whole. Items are rated on a 7-point Likert scale from 1 (Strongly Disagree) to 7 (Strongly Agree), with scores ranging from 5 to 35 , higher scores representing higher satisfaction with life. The SWLS was selected as a measure of convergent validity, as decreased suffering (and perhaps increased satisfaction with life) is an outcome of equanimity (Grabovac et al. 2011), and therefore, it would be expected that higher levels of equanimity would be associated with higher satisfaction with life. The SWLS has shown good internal consistency $(\alpha=.87)$ and good temporal stability $(r=$ .82 ) over 2 weeks (Diener et al. 1985), and good convergent validity and discriminant validity across a range of different populations (Pavot and Diener 1993).

\section{Distress Tolerance}

The Distress Tolerance Scale (DTS; Simons and Gaher 2005) is a 15-item self-report questionnaire assessing a person's ability to experience and withstand negative psychological states. Items are rated on a 5-point Likert scale from 1 (Strongly Agree) to 5 (Strongly Disagree), with scores ranging from 15 to 75 , higher scores representing greater tolerance for emotional distress. The DTS is comprised of a general distress tolerance factor and 4 subscales: tolerance (tolerance of emotional distress), absorption (absorbed in negative emotions), appraisal (appraisal of distress) and regulation (efforts to reduce distress). Given that the DTS has been shown to have the four subscales outlined above and a general distress tolerance factor (mean of the 4 subscales), both the overall distress tolerance factor and subscale scores were used in the analyses. The DTS was selected as a measure of convergent validity, as the ability to tolerate distress shares similarities with equanimity which involves non-reactivity to experiences. The DTS general distress tolerance factor has shown good internal consistency $(\alpha=.85)$ and the subscales were shown to yield acceptable to good internal consistency ( $\alpha=.73$ to $\alpha=.84$ ). Additionally, the DTS general distress tolerance factor has shown good stability and convergent, discriminant and criterion validity over a 6 -month period $(r=.61)$ in a sample of university students (Simons and Gaher 2005).

\section{Data Analyses}

Reverse scoring and computation of scale/subscale scores were completed for each measure. The underlying factor structure of the ES-42 was analyzed using exploratory factor analysis (EFA). Internal consistency was measured using Cronbach's Alpha. Partial Pearson's correlation coefficients were used to explore convergent and divergent validity. Participant responses between time points were matched and Pearson's correlation coefficients were used to assess testretest reliability.

\section{Results}

\section{Exploratory Factor Analysis}

EFA was conducted on the ES-42 using Principal Axis Factoring (PAF). Normality was assessed via visual inspection of the histograms, along with the Kolmogorov-Smirnov test, both suggesting a normal distribution, $D(223)=0.05, p=$ .200 . The Kaiser-Meyer-Olkin test $(\mathrm{KMO}=.91)$ and Bartlett's Test of Sphericity $\left(\chi^{2}(861)=4133.75, p<.001\right)$ suggested factor analysis was suitable. Concerns with multicollinearity were identified initially $\left(r^{2}<0.0001\right)$; however, this was reexamined after the final factor analysis with results suggesting no major concerns with multicollinearity $\left(r^{2}>0.0001\right)$. Velicer's Minimum Average Partial (Zwick and Velicer 1986) test suggested retaining two to three factors. EFAs were then conducted for two, three and four factor solutions with both Varimax and Direct Oblimin rotations, to determine which would be most interpretable. The Oblimin rotation was selected for the final analysis, given that factors are expected to be related. Examination revealed that the two-factor solution was the most interpretable, given that the other analyses did not result in four or more items on each factor with loadings $>.4$, after removing cross loadings. Items with the highest loadings for each factor were retained, resulting in a 2factor solution with eight items for each factor (see Table 2). We found each factor to be congruent with the theoretical assumptions of the construct. Item 28 was removed as it lacked specificity and replaced with item 21 (next highest loading) and item 15 was removed and replaced with item 23 , to ensure that items covered equanimity towards a range of experiences (e.g. equanimity towards things, sensations, thoughts, images, feelings). Additionally, the wording of one item was slightly changed to address conjugation errors at post data collection. These items are identified in Table 2. The EFA with PAF using Direct Oblimin rotation specifying two factors was performed on the 16 remaining items, which accounted for $48.02 \%$ of the variance. For convenience, this is henceforward referred to as the "Equanimity Scale-16" (ES-16). Inspection of the items suggested two overlapping factors $(r$ 
Table 2 Rotated factor loadings for the ES-16 items. Non-reactivity items are negatively worded

\begin{tabular}{|c|c|c|c|c|}
\hline $\begin{array}{l}\text { Item } \\
\text { number }\end{array}$ & Item & $\begin{array}{l}\text { Experiential } \\
\text { Acceptance }\end{array}$ & $\begin{array}{l}\text { Non- } \\
\text { reactivity }\end{array}$ & Original scale \\
\hline 11 & $\begin{array}{l}\text { When I experience distressing thoughts and images, I am able } \\
\text { to accept the experience (S) }\end{array}$ & .71 & -.04 & $\begin{array}{l}\text { Southampton Mindfulness } \\
\text { Questionnaire }\end{array}$ \\
\hline 9 & $\begin{array}{l}\text { I approach each experience by trying to accept it, no matter } \\
\text { whether it is pleasant or unpleasant (PT) }\end{array}$ & .66 & -.01 & Toronto Mindfulness Scale \\
\hline 27 & $\begin{array}{l}\text { When I have a distressing thought or image, I "step back" and } \\
\text { am aware of the thought or image without getting taken } \\
\text { over by it (CE) }\end{array}$ & .60 & .21 & Five Facet Mindfulness Questionnaire \\
\hline 3 & $\begin{array}{l}\text { When I have distressing thoughts or images, I am able just to } \\
\text { notice them without reacting }\end{array}$ & .63 & -.03 & Five Facet Mindfulness Questionnaire \\
\hline 13 & $\begin{array}{l}\text { I can pay attention to what is happening in my body without } \\
\text { disliking or wanting more of the feeling or sensation }\end{array}$ & .65 & -.01 & Multidimensional Mindfulness Inventory \\
\hline 33 & $\begin{array}{l}\text { I endeavour to cultivate calm and peace within me, even when } \\
\text { everything appears to be constantly changing }\end{array}$ & .52 & .06 & Multidimensional Mindfulness Inventory \\
\hline 21 & $\begin{array}{l}\text { I perceive my feelings and emotions without having to react } \\
\text { to them }\end{array}$ & .61 & .17 & Freiburg Mindfulness Inventory \\
\hline 23 & $\begin{array}{l}\text { I remain present with sensations and feelings even when they } \\
\text { are unpleasant }\end{array}$ & .62 & -.06 & Freiburg Mindfulness Inventory \\
\hline 16 & $\begin{array}{l}\text { When I notice my feelings, I have to act on them immediately } \\
\text { (S, PT) }\end{array}$ & -.16 & .75 & $\begin{array}{l}\text { Comprehensive Inventory of Mindfulness } \\
\text { Experiences Beta }\end{array}$ \\
\hline 26 & I notice that I need to react to whatever pops into my head (PT) & -.01 & .71 & Freiburg Mindfulness Inventory \\
\hline 36 & $\begin{array}{l}\text { I am impatient and can't stop my reactivity when faced with } \\
\text { other people's emotions and actions (PT) }\end{array}$ & .08 & .62 & Multidimensional Mindfulness Inventory \\
\hline 38 & $\begin{array}{l}\text { I am not able to prevent my reaction when someone is } \\
\text { unpleasant (PT) }\end{array}$ & -.05 & .62 & Multidimensional Mindfulness Inventory \\
\hline 18 & $\begin{array}{l}\text { If I notice an unpleasant body sensation, I tend to worry about } \\
\text { it (NW) }\end{array}$ & .26 & .47 & $\begin{array}{l}\text { Multidimensional Assessment of } \\
\text { Interoceptive Awareness }\end{array}$ \\
\hline 37 & I am not able to tolerate discomfort (NW) & .23 & .44 & Multidimensional Mindfulness Inventory \\
\hline 20 & $\begin{array}{l}\text { When I feel physical discomfort, I can't relax because I am never } \\
\text { sure it will pass (NW) }\end{array}$ & .22 & .40 & Mindfulness Self Efficacy Scale-Revised \\
\hline \multirow[t]{3}{*}{32} & $\begin{array}{l}\text { I can't keep my mind calm and clear, especially when I feel upset } \\
\text { or physically uncomfortable (NW) }\end{array}$ & .23 & .41 & Multidimensional Mindfulness Inventory \\
\hline & Eigenvalues & 5.95 & 1.73 & \\
\hline & Percentage of variance explained & 37.20 & 10.82 & \\
\hline
\end{tabular}

Note: 'S' denotes items that have been simplified for clarity, 'NW' denotes items that have been negatively worded, 'PT' denotes items changed in the present tense prior to data collection to improve interpretability and ' $\mathrm{CE}$ ' denotes items corrected for conjugation error. Factor loadings $>.40$ are in italic

$=.56$ ), sharing $31 \%$ variance, representing Experiential Acceptance and Non-reactivity. Items comprising the Nonreactivity factor were reverse scored to obtain the total scale score prior to analyses.

\section{Reliability}

Cronbach alpha was used to measure internal consistency of the items. Results are presented in Table 3. All scores were in the Acceptable to Excellent range. The alpha score for the ES16 was in the Good range (George and Mallery 2010).

\section{Convergent and Divergent Validity}

Visual inspection of the histograms for the ES-16 factors, NAS, MC-10, SWLS, DASS-21 subscales and DTS subscales revealed non-normal distributions and significant KMO values $(p<0.05)$. Accordingly, both Spearman (nonparametric) and Pearson (parametric) partial correlations between the above measures were calculated. As the parametric and non-parametric correlations were similar in magnitude and direction, Pearson's correlations are reported in the results below. Descriptive statistics for these measures are presented in Table 3.

Results of an independent samples $t$ test revealed no significant difference between males and female responses on total ES-16 $(t(221)=1.40, p=.164)$, Experiential Acceptance $(t(221)=0.99, p=.326)$, or Non-reactivity $(t(221)=1.48, p=.141)$. Results indicated a significant positive correlation between age and total ES-16 $(r=.28, p<.001)$, Experiential Acceptance $(r=.32, p<.001)$ and Non-reactivity $(r=.18, p<$ .001 ), showing that older age was more associated with higher equanimity scores. 
Table 3 Mean, standard deviation, minimum, maximum and Cronbach alpha of measures

\begin{tabular}{llllll}
\hline Scale & M & SD & Min & Max & $\alpha$ \\
\hline ES-16 & 58.76 & 10.36 & 23 & 78 & .88 \\
Experiential Acceptance & 29.59 & 5.71 & 9 & 40 & .85 \\
Non-reactivity & 29.17 & 5.99 & 12 & 40 & .82 \\
NAS & 4.67 & 0.73 & 2.20 & 5.90 & .94 \\
DASS-21 & & & & & \\
Depression & 3.26 & 3.35 & 0 & 18 & .89 \\
Anxiety & 2.86 & 2.95 & 0 & 14 & .79 \\
Stress & 5.56 & 3.23 & 0 & 19 & .82 \\
MC-10 & 5.38 & 2.38 & 0 & 10 & .70 \\
SWLS & 25.35 & 6.67 & 5 & 35 & .88 \\
DTS & 3.83 & 0.82 & 1 & 5 & .92 \\
Tolerance & 3.81 & 0.97 & 1 & 5 & .78 \\
Absorption & 3.74 & 1.01 & 1 & 5 & .82 \\
Appraisal & 3.99 & 0.83 & 1 & 5 & .83 \\
Regulation & 3.77 & 0.97 & 1 & 5 & .78 \\
\hline
\end{tabular}

ES-16, 16-item Equanimity Scale; NAS, Nonattachment Scale; DASS-21, Depression, Anxiety and Stress Scale; $M C$-10, Marlowe-Crowne Social Desirability Scale-Short Form; DTS, Distress Tolerance Scale

Results also indicated a significant positive correlation between social desirability (MC-10) and total ES-16 $(r=.36, p<$ $.001)$, Experiential Acceptance $(r=.38, p<.001)$ and Nonreactivity $(r=.25, p<.001)$. Therefore, age and social desirability were included as covariates in further analyses. Pearson's partial correlation coefficients controlling for age and socially desirable responding are presented in Table 4 .

Table 4 Relationship of the ES-16 with other constructs controlling for age and $\mathrm{MC}-10$

\begin{tabular}{lccc}
\hline & \multicolumn{2}{l}{ ES } & \\
\cline { 2 - 4 } & Total & Experiential Acceptance & Non-reactivity \\
\hline NAS & $.71^{*}$ & $.63^{*}$ & $.62^{*}$ \\
DASS-21 & & & \\
Depression & $-.37^{*}$ & $-.33^{*}$ & $-.32^{*}$ \\
Anxiety & $-.37^{*}$ & $-.30^{*}$ & $-.35^{*}$ \\
Stress & $-.44^{*}$ & $-.36^{*}$ & $-.40^{*}$ \\
SWLS & $.34^{*}$ & $.35^{*}$ & $.25^{*}$ \\
DTS & $.67^{*}$ & $.52^{*}$ & $.64^{*}$ \\
Tolerance & $.62^{*}$ & $.50^{*}$ & $.58^{*}$ \\
Absorption & $.62^{*}$ & $.49^{*}$ & $.58^{*}$ \\
Appraisal & $.54^{*}$ & $.47^{*}$ & $.48^{*}$ \\
Regulation & $.50^{*}$ & $.32^{*}$ & $.55^{*}$ \\
\hline
\end{tabular}

$* p<.001$

ES-16, 16-item Equanimity Scale; NAS, Nonattachment Scale; DASS-21, Depression, Anxiety and Stress Scale; DTS, Distress Tolerance Scale. Non-reactivity factor was reverse scored in the analysis
The ES-16 and its factors showed significant positive correlations with the NAS, SWLS and DTS and its subscales and a significant negative correlation with the DASS-21 subscales.

\section{Test-Retest Reliability}

Pearson's Correlation Coefficient was used to measure testretest reliability. Results showed a significant correlation between participant responses between time points for the ES-16 $(r=.87, p<.001)$ and its subscales, Experiential Acceptance $(r=.72, p<.001)$ and Non-reactivity $(r=.82, p<.001)$.

\section{Discussion}

The present study aimed to develop a self-report measure of equanimity, the Equanimity Scale-16 (ES-16; see final scale in the Appendix), and to explore its factor structure, reliability and validity in a general community sample. Consistent with hypotheses, results revealed two factors, Experiential Acceptance and Non-reactivity, accounting for $48 \%$ of the total variance. Experiential Acceptance involves acceptance of all internal experiences (thoughts, feelings, body sensations, etc.) and Non-reactivity relates to one's ability to inhibit a previously learned response to these experiences. Experiential Acceptance is the accompanying attitude that drives this (executive) effort. It can be conceptualized as the opposite of "experiential avoidance", which has been shown to be detrimental to well-being (Hayes et al. 1996). Acceptance has been shown to reduce reactivity (Lindsay and Creswell 2017; Lindsay et al. 2018), highlighting the interconnectedness of the two factors.

This operationalization is consistent with the Decoupling model of equanimity, proposing that equanimity involves acceptance (regardless of the hedonic tone) and reduced reactivity (Hadash et al. 2016). The two factors identified in the present study are also consistent with existing conceptualizations of equanimity (Desbordes et al. 2015; Hadash et al. 2016; Hart 1987). This operationalization of equanimity also fits within the BPM (Grabovac et al. 2011), the PROMISE model of insight and equanimity (Eberth et al. 2019), and the theoretical underpinnings of MiCBT (Cayoun 2011), as acceptance towards all experiences and non-reactivity to these experiences (equanimity), decrease habitual forms of craving and avoidance associated with suffering and other psychological symptoms. Additionally, the concepts of acceptance (Lindsay et al. 2018) and reactivity (Gu et al. 2015) have been identified as key mechanisms in MBIs. The ES-16 covers a large number of items that fit well with Hadash et al.'s observation that equanimity requires interoceptive acceptance regardless of the hedonic tone associated with the experience (Hadash et al. 2016). In particular, a number of items address equanimity towards body sensations, which has been 
identified as a key mechanism in both traditional teachings (Hart 1987) and in clinically oriented MBIs (Farb et al. 2015; Hölzel et al. 2011) given its interoceptive desensitization effects (Cayoun et al. 2019).

Many of the previous questionnaires with items assessing equanimity (Büssing et al. 2007; Kraus and Sears 2009; Lundman et al. 2007; Mack et al. 2008) tend to focus on the acceptance aspect of equanimity. This study has expanded on these conceptualizations by including a measure of non-reactivity, which is central to equanimity (Eberth et al. 2019) but generally missed in many definitions (Hadash et al. 2016). Behaviorally, preventing reactivity in the presence of an aversive experience is an important aspect of behavior change, requiring the inhibition of a conditioned response (reactivity). As such, the non-reactive component of equanimity may be understood as a key mechanism in the process of desensitization and has been proposed to be the principal active mechanism in MBIs (Cayoun et al. 2019; Desbordes et al. 2015). Just as patience is only needed and can only be developed when it is lacking, equanimity can only be cultivated where an unwanted prepotent response would otherwise occur automatically. Non-reactivity is developed through the necessity to override prepotent responses and prevent reinforcement. When examining the EBS (Weber and Lowe 2018), the interactive factor (representing attention and awareness) in particular appears to reflect awareness of and reactivity to experiences and low acceptance of internal experiences, sharing similarities with the present scale. However, the EBS measures barriers to equanimity, in contrast with assessing an individual's level of equanimity, which was the focus of the present study. Based on the above observations, there is minimal overlap between these existing scales and the ES-16.

The ES-16 and its factors, Experiential Acceptance and Non-reactivity, showed good internal consistency, suggesting that items are measuring the same construct within each factor. The ES-16 was found to have good test-retest reliability, which suggests that equanimity is relatively stable over 2 to 6 weeks. As such, it also suggests that equanimity may be best conceptualized as a trait developed over time, rather than a state which lacks stability. This view is in line with the frequent observation that MBIs tend to facilitate mood stability and have generally been shown to help prevent relapse (Kuyken et al. 2015).

Consistent with hypotheses, the total ES-16 scores and the scores for each factor showed significant associations in the expected directions with the other measures, showing good convergent and divergent validity. Specifically, responding with high levels of acceptance and non-reactivity towards experiences was significantly associated with higher levels of nonattachment to experiences. This relationship appeared to be one of the strongest associations, with large and significant correlations. This is probably because the constructs are similar. As previously suggested, nonattachment involves the attitude of not being fixated on experiences and not feeling a pressure to control these experiences (Sahdra et al. 2010), reflecting a degree of acceptance and non-reactivity.

Similarly, results showed that responding with high levels of acceptance and non-reactivity towards experiences was associated with higher levels of satisfaction with life. This relationship is consistent with the conceptualization of suffering as being the result of reactive responding to experiences, particularly craving positive experiences and avoiding negative ones (Teasdale and Chaskalson 2011). Since equanimity allows "a skillful emotional response to the full range of feeling tones" (Desbordes et al. 2015, p. 359), it decreases habitual patterns of responding, thereby reducing suffering (Cayoun 2011) and perhaps resulting in greater life satisfaction. Additionally, in states of high equanimity, desire is based on values and long-term goals (Hadash et al. 2016), which is a key component of Acceptance and Commitment Therapy, the aim of which is to create a rich, full and meaningful life (Hayes et al. 1999). A possible reason for which the relationship between the ES-16 and the SWLS was one of the weaker associations, showing small to medium correlations, may be that we do not always accept our experience and prevent reactivity out of a sense of fulfilment. Although equanimity tends to bring a sense of calmness and peace (Hart 1987), it may be perceived as a necessary and wise attitude (e.g. renouncing a destructive craving), but is not necessarily synonymous to joy and happiness in and of itself.

Moreover, the present results showed that responding with high levels of acceptance towards experiences and nonreactivity was strongly associated with higher levels of distress tolerance. This relationship is also likely to be due to the similarity of constructs in these two measures, as distress tolerance involves "the capacity to experience and withstand negative psychological states" (Simons and Gaher 2005, p. 83), and appears to reflect an attitude of acceptance towards unpleasant experiences (Hadash et al. 2016). However, it must be noted that adopting an equanimous attitude is not limited to destressing experiences. It equally applies to pleasant ones, during which applying equanimity prevents the tendency to attach oneself to the experience or crave it when it has subsided. Hence, equanimity also allows acceptance of the passing of pleasant events and the non-reactivity to their absence; it helps prevent the dissatisfaction and intolerance of the inability to obtain what is being desired.

As was hypothesized, the results also show that responding with higher levels of acceptance and non-reactivity towards experiences was associated with lower levels of depression, anxiety and stress symptoms, as shown by the significant negative correlations between all DASS and ES-16 subscales. This relationship is consistent with previously mentioned evidence that MBIs lead to symptom reduction in a range of psychological conditions (Baer 2003; Hofmann et al. 2010), and supports the view that equanimity is an active mechanism 
in MBIs (Cayoun 2011; Eberth et al. 2019). There was no effect of gender on participant responses. However, controlling for age revealed that participants tended to be more equanimous with age, as being less reactive and intolerant as one matures psychologically would be expected. This supports the ecological validity of the construct.

Additionally, there was a significant association between the ES-16 and social desirability, suggesting that those who scored highly on equanimity also scored highly on socially desirable responding. This association was controlled for in the analysis. Since it has been shown that social desirability also increases with age (Soubelet and Salthouse 2011), it is possible that the relationship between ES-16 scores and social desirability is mediated by age. Future studies will be needed to clarify this relationship.

We are aware that constructing a questionnaire using items from existing measures can lead to an inflation of number of scales measuring similar constructs. However, the ES-16 is only composed of one item from the Southampton Mindfulness Questionnaire, one item from the Toronto Mindfulness Scale, two items from the Five Facet Mindfulness Questionnaire, two items from the Freiburg Mindfulness Inventory, one item from the Comprehensive Inventory of Mindfulness Experiences Beta, one item from the Multidimensional Assessment of Interoceptive Awareness, two items from the Freiburg Mindfulness Inventory, One item from the Mindfulness Self Efficacy Scale-Revised and six items from the Multidimensional Mindfulness Inventory, which is an unpublished scale, only partly developed by one of the authors and colleagues with the intention to include an equanimity subscale - as for the other items of the MMI, these 6 items were selected by 13 lead authors (researchers, authors and traditional/ monastic teachers) in this field, from a very large pool constructed by this and other authors. As such, these six items do not contribute to a potential inflation of overlapping items across scales. This procedure was adopted in our study based on the observation that the selected items were conceptually congruent with the target construct and developing additional items would not have provided additional precisions or other advantages to the item pool. Rather, it would have more or less replicated them. The extraction of items from existing scales permits users to measure the single construct of equanimity with a significantly shorter number of items, unencumbered by items that may be irrelevant to what is needed to be measured. For example, Cayoun et al. (2019) examined the effects of equanimity in adults with moderate to severe chronic pain. Participants learned to self-implement interoceptive exposure to pain sensations while remaining equanimous, without any training in mindfulness. Consequently, mindfulness questionnaires (from which ES-16 items were extracted) were not used, as they were irrelevant and would have been inconsistent with hypotheses. A measure such as the ES-16 would be valuable in such cases.
The development of the ES-16 makes a unique empirical and theoretical contribution to the growing literature integrating Buddhist psychological constructs and clinical research. Given the increased recognition that equanimity is central to effective MBIs, the ability to measure this construct reliably is of significant assistance to both clinicians and researchers. Moreover, the ES-16 may be a more direct means of assessing whether equanimity is one of the central mechanisms of change in MBIs, which in turn can assist the development of more effective clinical interventions. For instance, some MBIs emphasize awareness of cognitive experience, whereas others emphasize acceptance of interoceptive experience. It is not clear whether these different emphases yield similar benefits. The ES-16 may also assist in examining the relevance of equanimity in models of mindfulness to allow further theoretical and empirical explorations of models such as the BPM (Grabovac et al. 2011), the PROMISE (Eberth et al. 2019) and the co-emergence model of reinforcement (Cayoun 2011).

\section{Limitations and Future Directions}

The present study contains several limitations. With regard to the sample, while participants were recruited from the general community, over half had post-graduate qualifications (a possible bias resulting from recruitment methods), about twothirds were female and a very high number identified as Caucasian, thereby limiting the generalizability of the results. Future replication studies would benefit from using more balanced samples and replications are needed in clinical samples. Although the sample size was acceptable given the ratio of cases by factors (Comfrey and Lee 1992; Tabachnick and Fidell 2001), it remains small by other standards (Nunnally 1978) and further studies with larger and more heterogenous samples would help confirm our findings. Additionally, despite good test-retest reliability, our assessment of temporal stability was not ideal, as a time interval that varied between 2 and 6 weeks between assessment points can affect the results, which should be prevented in future studies.

Further validation of the ES-16 is needed, including confirmatory factor analysis to confirm the factor structure, administration with other theoretically related constructs (such as suffering) and administration at pre- and post-mindfulness intervention, given that equanimity has been suggested to be a consequence of mindfulness training (Weber 2017). Future research would also benefit from using alternative models, such as a hierarchical model, to examine whether equanimity is a higher order factor, with Experiential Acceptance and Non-reactivity as lower order factors, as proposed by Hadash et al. (2016).

Finally, there are inherent limitations associated with the use of self-report questionnaires, particularly in the measurement of mindfulness, where it is not clear whether an individual can accurately report their own level of mindfulness (Grossman and van Dam 2011). In the present study, higher 
scores on equanimity were associated with higher scores on social desirability. It is not clear whether increased selfawareness through a mindfulness intervention would have reduced this bias. Further research would benefit from exploring this association, perhaps to determine whether social desirability decreases through the development of equanimity. If the correlations between the ES-16 and social desirability decrease as a function of increased equanimity, then social desirability could be taken as an additional measure during mindfulness training. Moreover, it is unclear whether this association would also be present in clinical samples, which is another avenue for future investigations.

Despite these limitations, the present study is an important first step in exploring the construct of equanimity and its underlying factors. Future research could assist in developing more objective ways of assessing equanimity, including behavioral, psychophysiological and imaging measures. For example, one of the biological correlates of reactivity being the amygdala activation following the detection of stressful triggers and mindfulness meditation has been shown to decrease grey matter volume in the right basolateral amygdala (Hölzel et al. 2011), improvement in equanimity on the ES-16 would be expected to correlate with reduction in amygdala volume.

Acknowledgements We thank Dr. Andrea Grabovac for her assistance with item selection.

Author Contributions HR: executed the study, analyzed the data and cowrote the paper. AS: co-designed the study and collaborated with the writing of the study and with the editing of the manuscript. BC: collaborated with the design and writing of the study and editing of the manuscript. All authors approved the final version of the manuscript for submission. This manuscript was completed in partial fulfilment of the requirement for the degree of Master of Clinical Psychology at the University of Technology Sydney, October 2018.

\section{Compliance with Ethical Standards}

Conflict of Interest The authors declare that they have no conflict of interest.

Informed Consent The study was approved by the Human Research Ethics Committee of the University of Technology Sydney, Australia (UTS HREC Ref 2015000482-74). Participants were fully informed of the procedure and aims of the study and gave their informed consent.

\section{Appendix}

\section{Equanimity Scale-16 (ES-16)}

Select the response that best describes how you view yourself, based on the scale below. Select the appropriate responses based on how much you agree with each statement right at this moment. Try not to spend too much time of any one item. There are no right or wrong answers.
- Strongly disagree $=1$

- Mildly disagree $=2$

- Agree and disagree equally $=3$

- Mildly agree $=4$

- Strongly agree $=5$

\begin{tabular}{|c|c|c|}
\hline $\begin{array}{l}\text { Item } \\
\text { number }\end{array}$ & Item & Subscale \\
\hline 1 & $\begin{array}{l}\text { When I experience distressing thoughts } \\
\text { and images, I am able to accept the } \\
\text { experience }\end{array}$ & $\begin{array}{l}\text { Experiential } \\
\text { Acceptance }\end{array}$ \\
\hline 2 & $\begin{array}{l}\text { I approach each experience by trying to } \\
\text { accept it, no matter whether it is pleasant } \\
\text { or unpleasant }\end{array}$ & $\begin{array}{l}\text { Experiential } \\
\text { Acceptance }\end{array}$ \\
\hline 3 & $\begin{array}{l}\text { When I have a distressing thought or } \\
\text { image, I "step back" and am aware of } \\
\text { the thought or image without getting } \\
\text { taken over by it }\end{array}$ & $\begin{array}{l}\text { Experiential } \\
\text { Acceptance }\end{array}$ \\
\hline 4 & $\begin{array}{l}\text { When I have distressing thoughts or } \\
\text { images, I am able just to notice them } \\
\text { without reacting }\end{array}$ & $\begin{array}{l}\text { Experiential } \\
\text { Acceptance }\end{array}$ \\
\hline 5 & $\begin{array}{l}\text { I can pay attention to what is happening in } \\
\text { my body without disliking or wanting } \\
\text { more of the feeling or sensation }\end{array}$ & $\begin{array}{l}\text { Experiential } \\
\text { Acceptance }\end{array}$ \\
\hline 6 & $\begin{array}{l}\text { I endeavor to cultivate calm and peace } \\
\text { within me, even when everything } \\
\text { appears to be constantly changing }\end{array}$ & $\begin{array}{l}\text { Experiential } \\
\text { Acceptance }\end{array}$ \\
\hline 7 & $\begin{array}{l}\text { I perceive my feelings and emotions } \\
\text { without having to react to them }\end{array}$ & $\begin{array}{l}\text { Experiential } \\
\text { Acceptance }\end{array}$ \\
\hline 8 & $\begin{array}{l}\text { I remain present with sensations and } \\
\text { feelings even when they are unpleasant }\end{array}$ & $\begin{array}{l}\text { Experiential } \\
\text { Acceptance }\end{array}$ \\
\hline 9 & $\begin{array}{l}\text { When I notice my feelings, I have to act on } \\
\text { them immediately }\end{array}$ & Non-reactivity \\
\hline 10 & $\begin{array}{l}\text { I notice that I need to react to whatever } \\
\text { pops into my head }\end{array}$ & Non-reactivity \\
\hline 11 & $\begin{array}{l}\text { I am impatient and can't stop my reactivity } \\
\text { when faced with other people's } \\
\text { emotions and actions }\end{array}$ & Non-reactivity \\
\hline 12 & $\begin{array}{l}\text { I am not able to prevent my reaction when } \\
\text { someone is unpleasant }\end{array}$ & Non-reactivity \\
\hline 13 & $\begin{array}{l}\text { If I notice an unpleasant body sensation, I } \\
\text { tend to worry about it }\end{array}$ & Non-reactivity \\
\hline 14 & I am not able to tolerate discomfort & Non-reactivity \\
\hline 15 & $\begin{array}{l}\text { When I feel physical discomfort, I can't } \\
\text { relax because I am never sure it will } \\
\text { pass }\end{array}$ & Non-reactivity \\
\hline 16 & $\begin{array}{l}\text { I can't keep my mind calm and clear, } \\
\text { especially when I feel upset or } \\
\text { physically uncomfortable }\end{array}$ & Non-reactivity \\
\hline
\end{tabular}

Items $9,10,11,12,13,14,15$ and 16 are reverse scored

\section{References}

Antony, M. M., Bieling, P. J., Cox, B. J., Enns, M. W., \& Swinson, R. P. (1998). Psychometric properties of the 42-item and 21-item versions of the Depression Anxiety Stress Scales in clinical groups and a community sample. Psychological Assessment, 10(2), 176-181. https://doi.org/10.1037/1040-3590.10.2.176. 
Baer, R. A. (2003). Mindfulness training as a clinical intervention: a conceptual and empirical review. Clinical Psychology: Science and Practice, 10(2), 125-143. https://doi.org/10.1093/clipsy. bpg015.

Baer, R. A., Smith, G. T., \& Allen, K. B. (2004). Assessment of mindfulness by self-report: The Kentucky Inventory of Mindfulness Skills. Assessment, 11(3), 191-206. https://doi.org/10.1177/ 1073191104268029.

Baer, R. A., Smith, G. T., Hopkins, J., Krietemeyer, J., \& Toney, L. (2006). Using self-report assessment methods to explore facets of mindfulness. Assessment, 13(1), 27-45. https://doi.org/10.1177/ 1073191105283504.

Baer, R. A., Walsh, E., \& Lykins, E. L. B. (2009). Assessment of mindfulness. In F. Didonna (Ed.), Clinical handbook of mindfulness (pp. 153-168). Springer. https://doi.org/10.1007/978-0-387-09593-6_ 10.

Bergomi, C., Tschacher, W., \& Kupper, Z. J. M. (2013a). The assessment of mindfulness with self-report measures: existing scales and open issues. Mindfulness, 4(3), 191-202. https://doi.org/10.1007/ S12671-012-0110-9.

Bergomi, C., Tschacher, W., \& Kupper, Z. (2013b). Measuring mindfulness: first steps towards the development of a comprehensive mindfulness scale. Mindfulness, 4, 18-32. https://doi.org/10.1007/ s12671-012-0102-9.

Bishop, S. R., Lau, M., Shapiro, S., Carlson, L., Anderson, N. D., Carmody, J., Segal, Z. V., Abbey, S., Speca, M., Velting, D., \& Devins, G. (2004). Mindfulness: a proposed operational definition. Clinical Psychology: Science and Practice, 11(3), 230-241. https:// doi.org/10.1093/clipsy.bph077.

Bodhi, B. (2000). A comprehensive manual of Abhidhamma: the philosophical psychology of Buddhism. Pariyatti Publishing.

Bodhi, B. (2005). In the Buddha's words: an anthology of discourses from the Pali Canon. Wisdom Publications.

Brown, K. W., \& Ryan, R. M. (2003). The benefits of being present: mindfulness and its role in psychological well-being. Journal of Personality and Social Psychology, 84(4), 822-848. https://doi. org/10.1037/0022-3514.84.4.822.

Brown, K. W., Ryan, R. M., \& Creswell, J. D. (2007). Mindfulness: theoretical foundations and evidence for its salutary effects. Psychological Inquiry, 18(4), 211-237. https://doi.org/10.1080/ 10478400701598298.

Buchheld, N., Grossman, P., \& Walach, H. (2001). Measuring mindfulness in insight meditation (Vipassana) and meditation-based psychotherapy: the development of the Freiburg Mindfulness Inventory (FMI). Journal of Meditation and Meditation Research, $1,5-23$.

Büssing, A., Ostermann, T., \& Matthiessen, P. F. (2007). Distinct expressions of vital spirituality: the ASP questionnaire as an explorative research tool. Journal of Religion and Health, 46(2), 267-286. https://doi.org/10.1007/s10943-006-9068-z.

Cardaciotto, L., Herbert, J. D., Forman, E. M., Moitra, E., \& Farrow, V. (2008). The assessment of present-moment awareness and acceptance. Assessment, 15(2), 204-223. https://doi.org/10.1177/ 1073191107311467.

Cayoun, B. A. (2011). Mindfulness-integrated CBT: Principles and practice. Wiley.

Cayoun, B. A., Francis, S. E., Kasselis, N., \& Skilbeck, C. (2012). The Mindfulness-based Self Efficacy Scale-revised. Retrieved from https://mindfulness.net.au/mindfulness-based-self-efficacy-scale. html.

Cayoun, B. A., Francis, S. E., \& Shires, A. G. (2019). The clinical handbook of Mindfulness-integrated Cognitive Behavior Therapy: a step-by-step guide for therapists. Wiley.

Cayoun, B. A., Simmons, A., \& Shires, A. (2020). Immediate and lasting chronic pain reduction following a brief self-implemented mindfulness-based interoceptive exposure task: a pilot study. Mindfulness, 11, 112-124. https://doi.org/10.1007/s12671-0170823-x.

Chadwick, P., Hember, M., Symes, J., Peters, E., Kuipers, E., \& Dagnan, D. (2008). Responding mindfully to unpleasant thoughts and images: reliability and validity of the Southampton Mindfulness Questionnaire (SMQ). British Journal of Clinical Psychology, 47(4), 451-455. https://doi.org/10.1348/014466508X314891.

Comfrey, A. L., \& Lee, H. B. (1992). A first course in factor analysis. Lawrence Erlbaum.

Desbordes, G., Gard, T., Hoge, E. A., Hölzel, B. K., Kerr, C., Lazar, S. W., Olendzki, A., \& Vago, D. R. (2015). Moving beyond mindfulness: defining equanimity as an outcome measure in meditation and contemplative research. Mindfulness, 6(2), 356-372. https://doi.org/ 10.1007/s12671-013-0269-8.

Diener, E., Emmons, R. A., Larson, R. J., \& Griffin, S. (1985). The Satisfaction with Life Scale. Journal of Personality Assessment, 49, 71-76. https://doi.org/10.1207/s15327752jpa4901_13.

Dyer, A., \& Cayoun, B. (2012). Multidimensional Mindfulness Inventory. Unpublished manuscript available from the authors.

Eberth, J., Sedlmeier, P., \& Schafer, T. (2019). PROMISE: a model of insight and equanimity as the key effects of mindfulness meditation. Frontiers in Psychology, 10, 2389. https://doi.org/10.3389/fpsyg. 2019.02389 .

Farb, N., Daubenmier, J., Price, C. J., Gard, T., Kerr, C., Dunn, B. D., Klein, A. C., Paulus, M. P., \& Mehling, W. E. (2015). Interoception, contemplative practice, and health. Frontiers in Psychology, 6, 763. https://doi.org/10.3389/fpsyg.2015.00763.

Feldman, G., Hayes, A., Kumar, S., Greeson, J., \& Laurenceau, J. P. (2007). Mindfulness and emotion regulation: the development and initial validation of the Cognitive and Affective Mindfulness ScaleRevised (CAMS-R). Journal of Psychopathology and Behavioral Assessment, 29(3), 177-190. https://doi.org/10.1007/s10862-0069035-8.

Fischer, D. G., \& Fick, C. (1993). Measuring social desirability: short forms of the Marlow Crowne Social Desirability Scale. Educational and Psychological Measurement, 53(2), 417-424. https://doi.org/ $10.1177 / 0013164493053002011$.

Fresco, D. M., Moore, M. T., van Dulmen, M. H. M., Segal, Z. V., Ma, S. H., Teasdale, J. D., \& Williams, J. M. G. (2007). Initial psychometric properties of the Experiences Questionnaire: validation of a selfreport measure of decentering. Behavior Therapy, 38(3), 234-246. https://doi.org/10.1016/j.beth.2006.08.003.

George, D., \& Mallery, P. (2010). SPSS for Windows step by step: a simple guide and reference, 17.0 update (10th). Pearson.

Grabovac, A. D., Lau, M. A., \& Willett, B. R. (2011). Mechanisms of mindfulness: a Buddhist psychological model. Mindfulness, 2(3), 154-166. https://doi.org/10.1007/s12671-011-0054-5.

Gratz, K. L., \& Roemer, L. (2004). Multidimensional assessment of emotion regulation and dysregulation: development, factor structure, and initial validation of the Difficulties in Emotion Regulation Scale. Journal of Psychopathology and Behavioral Assessment, 26, 4154. https://doi.org/10.1023/B:JOBA.0000007455.08539.94.

Grossman, P. (2011). Defining mindfulness by how poorly I think I pay attention during everyday awareness and other intractable problems for psychology's (re)invention of mindfulness: comment on Brown et al. (2011). Psychological Assessment, 23(4), 1034-1040. https:// doi.org/10.1037/a0022713.

Grossman, P., \& van Dam, N. T. (2011). Mindfulness, by any other name...: trials and tribulations of sati in western psychology and science. Contemporary Buddhism, 12, 219-239. https://doi.org/10. 1080/14639947.2011.564841.

Gu, J., Strauss, C., Bond, R., \& Cavanagh, K. (2015). How do mindfulness-based cognitive therapy and mindfulness-based stress reduction improve mental health and wellbeing? A systematic 
review and meta-analysis of mediation studies. Clinical Psychology Review, 37, 1-12. https://doi.org/10.1016/j.cpr.2015.01.006.

Hadash, Y., Segev, N., Tanay, G., Goldstein, P., \& Bernstein, A. (2016). The decoupling model of equanimity: theory, measurement, and test in a mindfulness intervention. Mindfulness, 7(5), 1214-1226. https://doi.org/10.1007/s12671-016-0564-2.

Hart, W. (1987). The art of living: Vipassana meditation as taught by S. N. Goenka. Harper \& Row.

Hayes, S. C., Wilson, K. G., Gifford, E. V., Follette, V. M., \& Strosahl, K. (1996). Experiential avoidance and behavioral disorders: a functional dimensional approach to diagnosis and treatment. Journal of Consulting and Clinical Psychology, 64(6), 1152-1168. https:// doi.org/10.1037//0022-006x.64.6.1152.

Hayes, S. C., Strosahl, K., \& Wilson, K. G. (1999). Acceptance and commitment therapy: an experiential approach to behavior change. Guilford Press.

Hofmann, S. G., Sawyer, A. T., Witt, A. A., \& Oh, D. (2010). The effect of mindfulness-based therapy on anxiety and depression: a metaanalytic review. Journal of Consulting and Clinical Psychology, 78(2), 169-183. https://doi.org/10.1037/a0018555.

Hölzel, B. K., Lazar, S. W., Gard, T., Schuman-Olivier, Z., Vago, D. R., \& Ott, U. (2011). How does mindfulness meditation work? Proposing mechanisms of action from a conceptual and neural perspective. Perspectives on Psychological Science, 6(6), 537-559. https://doi.org/10.1177/1745691611419671.

Kabat-Zinn, J. (1990). Full catastrophe living: using the wisdom of your body and mind to face stress, pain, and illness. Delacorte Press.

Kabat-Zinn, J. (1994). Wherever you go, there you are: mindfulness meditation in everyday life. Hyperion.

Kohn, P. M., O’brien-Wood, C., Pickering, D. I., \& Decicco, T. L. (2003). The Personal Functioning Inventory: a reliable and valid measure of adaptiveness in coping. Canadian Journal of Behavioural Science, 35(2), 111-123. https://doi.org/10.1037/ h0087193.

Kraus, S., \& Sears, S. (2009). Measuring the immeasurables: development and initial validation of the Self-Other Four Immeasurables (SOFI) scale based on Buddhist teachings on loving kindness, compassion, joy, and equanimity. Social Indicators Research, 92(1), 169-181. https://doi.org/10.1007/ s11205-008-9300-1.

Kuyken, W., Hayes, R., Barrett, B., Byng, R., Dalgleish, T., Kessler, D., Lewis, G., Watkins, E., Brejcha, C., Cardy, J., Causley, A., Cowderoy, S., Evans, A., Gradinger, F., Kaur, S., Lanham, P., Morant, N., Richards, J., Shah, P., et al. (2015). Effectiveness and cost-effectiveness of mindfulness-based cognitive therapy compared with maintenance antidepressant treatment in the prevention of depressive relapse or recurrence (PREVENT): a randomised controlled trial. Lancet, 386(9988), 63-73. https://doi.org/10.1016/ S0140-6736(14)62222-4.

Lau, M. A., Bishop, S. R., Segal, Z. V., Buis, T., Anderson, N. D., Carlson, L., Shapiro, S., Carmody, J., Abbey, S., \& Devins, G. (2006). The Toronto Mindfulness Scale: development and validation. Journal of Clinical Psychology, 62(12), 1445-1467. https:// doi.org/10.1002/jclp.20326.

Lindsay, E. K., \& Creswell, J. D. (2017). Mechanisms of mindfulness training: monitor and acceptance theory (MAT). Clinical Psychology Review, 51, 48-59. https://doi.org/10.1016/j.cpr.2016. 10.011 .

Lindsay, E., Young, S., Smyth, J., Brown, K., \& Creswell, D. (2018). Acceptance lowers stress reactivity: dismantling mindfulness training in a randomized controlled trial. Psychoneuroendocrinology, 87, 63-73. https://doi.org/10.1016/j.psyneuen.2017.09.015.

Lovibond, S. H., \& Lovibond, P. F. (1995). Manual for the Depression Anxiety Stress Scales (2nd ed.). Psychology Foundation, University of New South Wales.
Lundman, B., Strandberg, G., Eisemann, M., Gustafson, Y., \& Brulin, C. (2007). Psychometric properties of the Swedish version of the Resilience Scale. Scandinavian Journal of Caring Sciences, 21(2), 229-237. https://doi.org/10.1111/j.14716712.2007.00461.x.

Mack, J. W., Nilsson, M., Balboni, T., Friedlander, R. J., Block, S. D., Trice, E., \& Prigerson, H. G. (2008). Peace, equanimity, and acceptance in the cancer experience (PEACE): validation of a scale to assess acceptance and struggle with terminal illness. Cancer, 112(11), 2509-2517. https://doi.org/10.1002/cncr.23476.

Mehling, W., Price, C., Daubenmier, J., Acree, M., Bartmess, E., \& Stewart, A. (2012). The Multidimensional Assessment of Interoceptive Awareness (MAIA). PLoS One, 7(11), e0208034. https://doi.org/10.1371/journal.pone.0048230.

Monteiro, L., \& Musten, F. (2013). Mindfulness starts here: an eightweek guide to skillful living. Friesen Press.

Nunnally, J. O. (1978). Psychometric theory. McGraw-Hill.

Pavot, W., \& Diener, E. (1993). Review of the Satisfaction With Life Scale. Psychological Assessment, 5(2), 164-172. https://doi.org/10. 1037/1040-3590.5.2.164.

Pirson, M. A., \& Langer, E. (2015). Developing the Langer Mindfulness Scale. Academy of Management Proceedings, 2015(1), 11308. https://doi.org/10.5465/AMBPP.2015.11308abstract.

Quaglia, J. T., Brown, K. W., Lindsay, E. K., Creswell, J. D., \& Goodman, R. J. (2015). From conceptualization to operationalization of mindfulness. In K. W. Brown, D. J. Creswell, \& R. M. Ryan (Eds.), Handbook of mindfulness: theory, research, and practice (pp. 151-170). The Guilford Press.

Sahdra, B. K., Shaver, P. R., \& Brown, K. W. (2010). A scale to measure nonattachment: a Buddhist complement to western research on attachment and adaptive functioning. Journal of Personality Assessment, 92, 116-127. https://doi.org/10.1080/ 00223890903425960.

Segal, Z. V., Williams, J. M. G., \& Teasdale, J. D. (2002). MindfulnessBased Cognitive Therapy for depression: a new approach to preventing relapse. Guilford Press.

Shapiro, S. L., Carlson, L. E., Astin, J. A., \& Freedman, B. (2006). Mechanisms of mindfulness. Journal of Clinical Psychology, 62(3), 373-386. https://doi.org/10.1002/jclp.20237.

Shonin, E., Van Gordon, W., Dunn, T., Singh, N., \& Griffiths, M. (2014). Meditation awareness training (MAT) for work-related well-being and job performance: a randomized controlled trial. International Journal of Mental Health and Addiction, 12, 806-823. https://doi. org/10.1007/s11469-014-9513-2.

Simons, J. S., \& Gaher, R. M. (2005). The Distress Tolerance Scale: Development and validation of a self-report measure. Motivation and Emotion, 29(2), 83-102. https://doi.org/10.1007/s11031-0057955-3.

Singh, N., Lancioni, G., Winton, A., Karazsia, B., Myers, R., Latham, L., \& Singh, J. (2014). Mindfulness-Based Positive Behavior Support (MBPBS) for mothers of adolescents with autism spectrum disorder: effects on adolescents' behavior and parental stress. Mindfulness, 5, 646-657. https://doi.org/ 10.1007/s12671-014-0321-3.

Soubelet, A., \& Salthouse, T. A. (2011). Influence of social desirability on age differences in self-reports of mood and personality. Journal of Personality, 79, 741-762. https://doi.org/10.1111/j.1467-6494. 2011.00700.x

Strahan, R., \& Gerbasi, K. C. (1972). Short, homogeneous version of the Marlow-Crowne Social Desirability Scale. Journal of Clinical Psychology, 28(2), 191-193.

Tabachnick, B. G., \& Fidell, L. S. (2001). Using multivariate statistics (4th ed.) Pearson.

Tanay, G., \& Bernstein, A. (2013). State Mindfulness Scale (SMS): development and initial validation. Psychological Assessment, 25(4), 1286-1299. https://doi.org/10.1037/a0034044. 
Teasdale, J. D., \& Chaskalson, M. (2011). How does mindfulness transform suffering? II: the transformation of dukkha. Contemporary Buddhism, 12(1), 103-124. https://doi.org/10.1080/14639947. 2011.564826

Wagnild, G., \& Young, H. (1993). Development and psychometric evaluation of the Resilience Scale. Journal of Nursing Measurement, 1(2), 165-178

Weber, J. (2017). Mindfulness is not enough: why equanimity holds the key to compassion. Mindfulness \& Compassion, 2(2), 149-158. https://doi.org/10.1016/j.mincom.2017.09.004.

Weber, J., \& Lowe, M. (2018). Development and validation of the Equanimity Barriers Scale [EBS]. Current Psychology, 1-15. https://doi.org/10.1007/s12144-018-9969-5.
Williams, J. M. G., \& Kabat-Zinn, J. (2011). Mindfulness: diverse perspectives on its meaning, origins, and multiple applications at the intersection of science and dharma. Contemporary Buddhism, 12(1), 1-18. https://doi.org/10.1080/14639947.2011.564811.

Zwick, W. R., \& Velicer, W. F. (1986). Comparison of five rules for determining the number of components to retain. Psychological Bulletin, 99(3), 432-442. https://doi.org/10.1037/0033-2909.99.3. 432.

Publisher's Note Springer Nature remains neutral with regard to jurisdictional claims in published maps and institutional affiliations. 